\title{
Rancang Bangun Mesin 3D Printer dan Laser Engraver Berbasis Arduino
}

\author{
Yosef Teddy Budianto, Arka Dwinanda Soewono, Marten Darmawan* \\ Program Studi S1 Teknik Mesin, Fakultas Teknik, Universitas Katolik Indonesia Atma Jaya \\ Jl. Raya Cisauk Lapan, Cisauk, Tangerang, Banten 15345 \\ *E-mail: marten.darmawan@atmajaya.ac.id
}

\begin{abstract}
Abstrak
Dalam industri manufaktur modern, 3D Printer dan Laser Engraver merupakan dua fungsi dasar yang dapat mewujudkan objek rancangan $3 \mathrm{D}$ sesuai dengan fungsi yang diinginkan secara cepat dan ekonomis. Meskipun demikian, secara umum dalam prakteknya seringkali kedua fungsi tersebut hanya dapat dipenuhi oleh dua jenis alat berbeda. Tentu saja hal ini akan berdampak pada tingginya biayabiaya yang dikeluarkan oleh pelaku-pelaku industri manufaktur, baik dari segi biaya operasional, biaya pengadaan, waktu produksi dan lain sebagainya. Oleh karena itu, diperlukan perancangan alat berbiaya rendah yang dapat mengintegrasikan dua fungsi yaitu 3D Printer dan Laser Engraving. Dalam penelitian ini dilakukan perancangan sistem alat yang dapat mengintegrasikan fungsi 3D printer dan Laser Engraver dengan hanya memvariasikan head sehingga dalam penggunaanya, head dapat diganti dari 3D Printer ke Laser Engraver dan juga sebaliknya. Pengujian fungsi 3D printer dilakukan berdasarkan fenomena bridging, overhang, dan oozebane melalui variasi parameter sehingga dihasilkan pengaturan optimal pada suhu hotend $185^{\circ} \mathrm{C}$, suhu heated bed $50^{\circ} \mathrm{C}$ dan feedrate cetak 25 $\mathrm{mm} /$ min sehingga didapat akurasi dan kepresisian pada proses $3 D$ Printer dengan material PLA sebesar 0,1 mm. Sedangkan pada pengujian fungsi Laser Engraver didapat penandaan (marking) yang optimal pada jarak head laser $75 \mathrm{~mm}$, sedangkan kecepatan gerak optimum pada material kardus sebesar $400 \mathrm{~mm} / \mathrm{min}$, dan material triplek pada $300 \mathrm{~mm} / \mathrm{min}$.
\end{abstract}

Kata kunci: laser engraver; multifunction $C N C$; $3 D$ printer

\begin{abstract}
In the modern manufacturing industries, $3 D$ Printer and Laser Engraver are two basic functions that can realize a $3 D$ design object according to the desired function quickly and economically. However, in general and in practice these two functions can only be fulfilled by two different types of tools. Of course, this will have an impact on the high costs incurred by manufacturing industry players, both in terms of operational costs, procurement costs, production time, and so on. Therefore, it is necessary to design a low-cost device that can integrate two functions, namely $3 D$ Printer and Laser Engraving. In this research, the design of a system tool that can integrate the functions of a 3D printer and Laser Engraver is carried out by only varying the head so that in use, the head can be replaced from a $3 D$ Printer to a Laser Engraver and vice versa. Testing of $3 D$ printer functions was carried out based on the phenomenon of bridging, overhang, and oozebane through various parameters so that the optimal settings were produced at temperature hot end $185^{\circ} \mathrm{C}$, heated bed $50^{\circ} \mathrm{C}$ and a feed rate print of 25 $\mathrm{mm} / \mathrm{min}$ so that the accuracy and precision of the process $3 D$ Printer with PLA material was $0.1 \mathrm{~mm}$. Meanwhile, in testing the function of the Laser Engraver, the marking was optimal at a distance head laser of $75 \mathrm{~mm}$, while the optimum speed of movement for material kardus was $400 \mathrm{~mm} / \mathrm{min}$, and material triplek was $300 \mathrm{~mm} / \mathrm{min}$.
\end{abstract}

Keywords: laser engraver; multifunction $C N C$; $3 D$ printer

\section{Pendahuluan}

Pada era modern saat ini, perancangan alat sudah berkembang dengan pesat. Perancangan yang dahulu hanya menggunakan cara manual dalam permodelan 2D saat ini sudah berubah menggunakan perangkat lunak / komputer dalam permodelan 2D hingga 3D. 3D Printer hadir sebagai alat yang dapat mewujudkan objek rancangan sehingga sebuah rancangan dapat direalisasikan sesuai dengan fungsi yang sebenarnya secara cepat dan ekonomis. $3 D$ Printer tujuan awalnya digunakan untuk pembuatan purwarupa secara cepat saat ini secara progresif mengambil bagian yang lebih penting dalam proses manutaktur [1]. 3D Printer sudah banyak digunakan bukan hanya sebatas purwarupa namun 
hasil cetaknya dapat langsung digunakan. Dengan adanya $3 D$ Printer objek yang rumit jika dikerjakan melalui proses milling dan turning dapat menjadi lebih mudah direalisasikan.

Kerajinan berbahan dasar kulit banyak menggunakan proses penandaan panas untuk memberikan pola berupa gambar, tulisan, dan merk pada bahan kulit. Proses penandaan dengan prinsip penorehan panas secara manual memerlukan keahlian dan keahlian dalam proses pengerjaanya karena beresiko pola yang digambar dapat meleset. Saat ini dengan ada nya mesin CNC Laser Engraver, penggunaanya dapat dilakukan pada kerajinan berbahan dasar kulit. Mesin CNC Laser Engraver dapat digunakan untuk menggambar pola pada objek sehingga dapat menambahkan unsur ketepatan tanpa mengurangi estetika. Dengan alasan tersebut mesin CNC Laser Engraver adalah solusi teknologi yang dapat membuat proses penandaan panas dengan lebih cepat dan berkualitas sehingga mengurangi barang NG (Not Good) [2].

Pelaku usaha jasa $3 D$ Printer yang saat ini juga merambah ke jasa lain seperti jasa router dan laser untuk menambah produktifitas usaha yang masih tergolong dalam sektor usaha yang sama yaitu sektor manufaktur. Pelaku usaha memilih Laser Engraver dibandingkan router karena dapat digabungkan dengan mesin 3D Printer dan merupakan salah satu jenis substractive manufacturing yang tidak menghasilkan material chip dan suara layaknya router [3]. Berdasarkan kebutuhan tersebut dibuatlah mesin dimana mekanisme mekaniknya sama dan terdiri dari dua head berbeda. Sehingga dalam penggunaanya head dapat diganti dari 3D Printer ke Laser Engraver dan juga sebaliknya. Laser Engraver yang dijadikan satu dengan $3 D$ Printer memiliki beberapa keuntungan diantaranya dengan adanya sumbu Z, Laser Engraver dapat melakukan penandaan pada objek dengan ketebalan variatif, lebih hemat tempat, dapat menekan biaya sehingga lebih terjangkau dan mesin menjadi multifungsi.

Dalam penelitian ini dilakukan proses rancang bangun 3D Printer yang memiliki beberapa keuntungan dibandingkan membeli mesin $3 D$ Printer komersil. Dalam proses rancang bangun, komponen yang digunakan dapat dipastikan ketersediaanya di Indonesia dan perancangan komponen kontrol dilakukan secara mandiri sehingga ketika terjadi maintenance akan lebih mudah dibandingkan untuk melakukan penelusuran kerusakan dan perbaikan mesin. Selain itu, 3D printer yang dirancang memiliki keunggulan pada sisi fungsionalnya yaitu dapat digunakan sebagai laser engraver melalui penggantian unit kepala ekstruder dengan unit kepala laser. Mesin 3D Printer maupun Laser Engraver termasuk dalam mesin CNC yang didesain untuk mampu bekerja terus menerus dan minim akan downtime. Maka dari itu ketika terjadi kerusakan komponen harus dapat dengan mudah dilakukan penggantian serta komponennya tersedia dipasaran. Sedangkan pada mesin $3 D$ Printer yang dijual dipasaran tidak ada jaminan akan ketersediaan komponenkomponen nya karena machine maker biasanya menjual satu set mesin. Apabila sudah demikian maka mesin yang dibeli dari machine maker dan mengalami kerusakan dikemudian hari akan menjadi tidak dapat berfungsi kembali dan berakibat pada pembengkakan biaya untuk pengadaan mesin baru.

\section{Material dan metode penelitian}

Proses perancangan untuk pembuatan mesin $3 D$ Printer dan Laser Engraver berbasis Arduino dimulai dengan menentukan wish and demand yang sesuai dengan kebutuhan (Gambar 1). Setelah didapati wish and demand yang sesuai maka selanjutnya dibuat desain matriks dengan beberapa opsi sehingga komponen-komponen penting pada mesin dapat sesuai dan tidak over specification dilihat berdasarkan wish and demand. Komponen yang telah dipilih dilakukan fabrikasi dan dirakit baik untuk komponen mekanik maupun elektrik. Sebelum pengujian, instalasi firmware pada kontroler dan konfigurasi sesuai dengan aktuator yang digunakan dilakukan terlebih dahulu. 
Langkah selanjutnya yaitu melakukan uji fungsi $3 D$ Printer dan Laser Engraver apakah sudah berfungsi sesuai dengan kebutuhan. Pada uji fungsi 3D Printer dilakukan beberapa pengaturan parameter untuk memaksimalkan hasil dan kepresisian mesin hingga mencapai ketelitian $<0,15 \mathrm{~mm}$. Sedangkan pada uji fungsi Laser Engraver akan dilakukan pengaturan jarak dan kecepatan gerak pengukiran hingga menghasilkan garis penandaan yang tegas dan konsisten. Data penelitian diambil secara pararel saat melakukan uji fungsi untuk dilakukan analisis apakah pengaturan yang diuji berpengaruh terhadap hasil objek dan juga untuk menentukan karakteristik pada mesin yang dibuat.

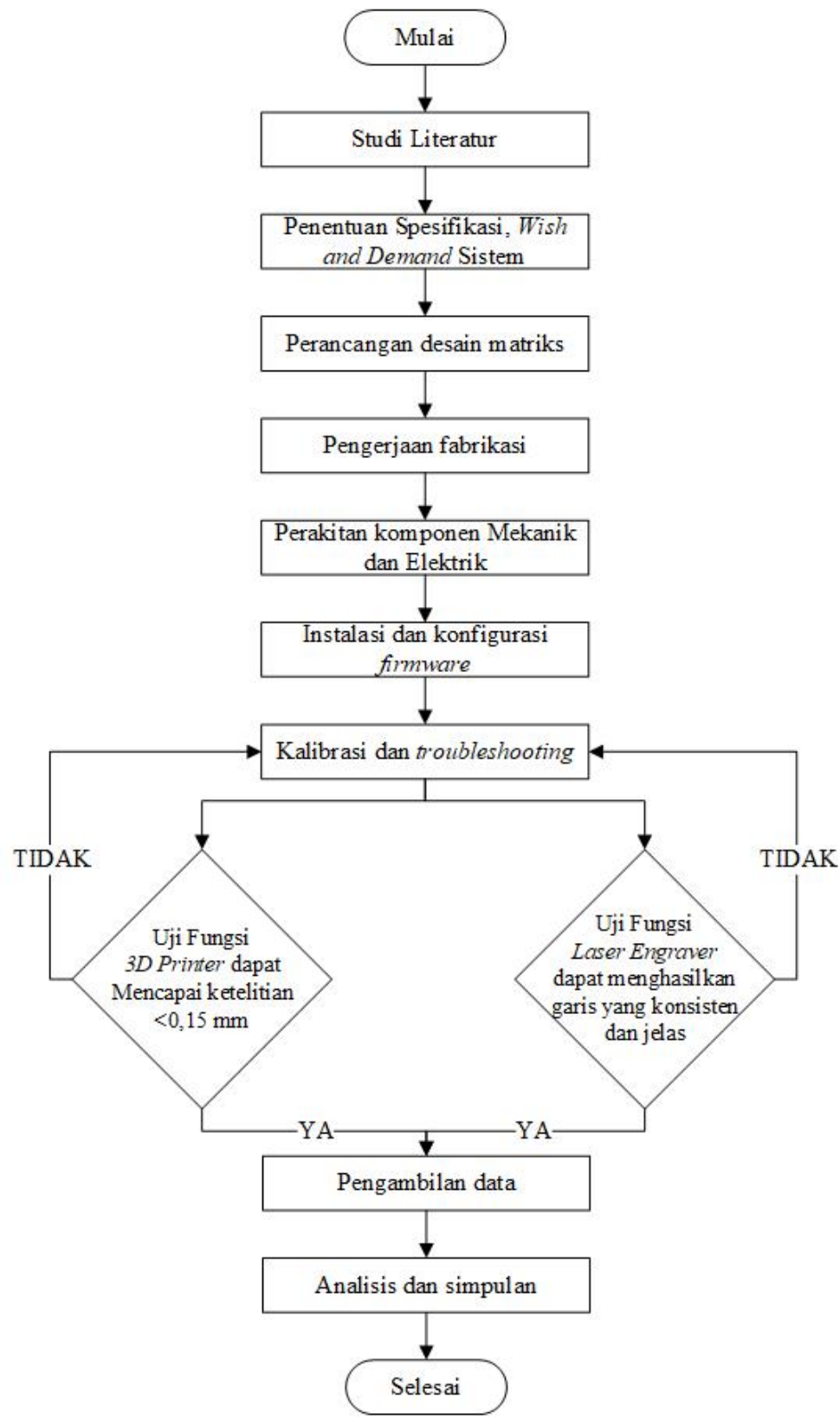

Gambar 1. Diagram alir penelitian

\section{Hasil dan Pembahasan}

Data penelitian diambil secara pararel saat melakukan uji fungsi untuk dilakukan analisis apakah pengaturan yang diuji berpengaruh terhadap hasil objek dan juga untuk menentukan karakteristik pada mesin yang dibuat baik untuk fungsi 3D Printer maupun Laser Engraver. 
Yosef Teddy Budianto dkk /Jurnal Rekayasa Mesin

p-ISSN: 1411-6863, e-ISSN: 2540-7678

Vol.15|No.3|183-190|Desember|2020

\subsection{Perwujudan Alat}

Hasil desain dan perwujudan alat yang telah dirancang ditunjukkan pada Gambar 2, dimana alat yang dirancang memiliki fungsi sebagai 3D Printer maupun Laser Engraver. Alat yang telah dirancang dapat dengan mudah dan murah untuk diperbaiki dan dimodifikasi untuk keperluan manufaktur benda dengan spesifikasi-spesifikasi yang lain.

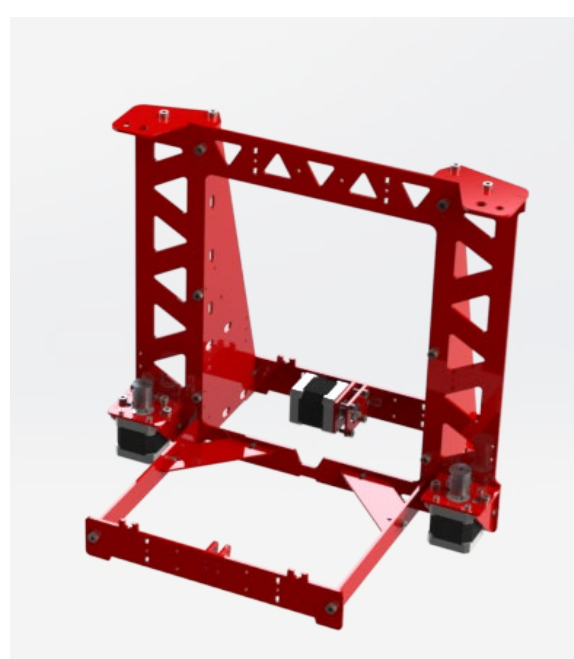

(a)

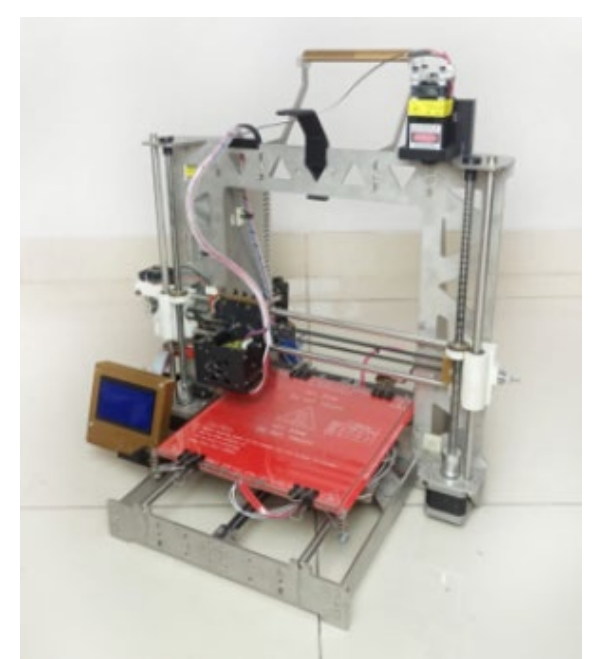

(b)

Gambar 2. (a) Desain alat dan (b) Perwujudan alat

\subsection{Bridging}

Bridging adalah kondisi dimana ketika filamen yang dicetak menyambungkan dua titik secara horizontal yang tidak terdapat filamen diantara dua titik tersebut. Untuk memaksimalkan bridging dapat dilakukan dengan menurunkan bridge flow ratio dan menaikan bridge feedrate. Berikut merupakan nilai pengaturan yang digunakan pada pengujian bridging (Tabel 1).

Tabel 1. Hasil Pengujian Bridging

\begin{tabular}{clll}
\hline No. & & Parameter & Hasil \\
\hline 1 & - Bridge feedrate & $=30 \mathrm{~mm} / \mathrm{min}$ \\
& - Bridge flow ratio & $=100 \%$ \\
& - Hotend temperature & $=185^{\circ} \mathrm{C}$ \\
& - Bed temperature & $=50^{\circ} \mathrm{C}$ \\
2 & - Bridge feedrate & $=60 \mathrm{~mm} / \mathrm{min}$ \\
& - Bridge flow ratio & $=100 \%$ \\
& - Hotend temperature & $=185^{\circ} \mathrm{C}$ \\
& - Bed temperature & $=50^{\circ} \mathrm{C}$ \\
3 & - Bridge feedrate & $=60 \mathrm{~mm} / \mathrm{min}$ \\
& - Bridge flow ratio & $=75 \%$ \\
& - Hotend temperature & $=185^{\circ} \mathrm{C}$ \\
& - Bed temperature & $=50^{\circ} \mathrm{C}$
\end{tabular}

Bridge feedrate merupakan parameter yang mengatur kecepatan cetak pada saat terdapat bagian bridging. Pada pengujian ke-1 dengan pengaturan bridge feedrate $30 \mathrm{~mm} / \mathrm{min}$ terdapat filamen yang terjatuh. Setelah itu pengujian ke2 nilai bridge feedrate dinaikan menjadi $60 \mathrm{~mm} / \mathrm{min}$ dan terihat lebih sedikit filamen saja yang masih terjatuh kebawah. Dapat dilihat dari hasil pengujian, kecepatan yang terlalu rendah dapat mengakibatkan filamen terjatuh. Hal ini 
disebabkan saat nozzle bergerak terlalu lambat filamen yang di extrude akan tergantung di udara terlalu lama dan akan jatuh kebawah.

Bridge flow ratio merupakan pengaturan rasio filamen yang dikeluarkan oleh ekstruder saat mencetak bagian bridging. Selanjutnya pada pengujian ke-3 dilakukan pengurangan nilai bridge flow ratio menjadi $75 \%$ dan dihasilkan objek cetak bridging yang paling baik dibandingkan sebelumnya. Untuk menghasilkan celah bridging yang baik filamen harus set dalam waktu yang cepat, sehingga ketika terlalu banyak filamen leleh mengalir dari nozzle dapat menyebabkan hasil cetak seperti jembatan yang menggantung kebawah. Atur bridge flow ratio sampai nozzle mengeluarkan filamen dengan stabil dan lebih mudah dingin sehingga menghasilkan bridging baik.

PLA 4032D memiliki $T_{m}$ (suhu leleh) $170^{\circ} \mathrm{C}$. Pada pengujian digunakan suhu cetak $185^{\circ} \mathrm{C}\left(\mathrm{T}_{\mathrm{m}}+15^{\circ} \mathrm{C}\right)$ untuk memastikan semua filamen yang melewati nozzle sudah dalam fase leleh, apabila proses cetak dilakukan dibawah suhu tersebut dapat menyebabkan material tidak seluruhnya meleleh sehingga terjadi penyumbatan pada nozzle. Proses cetak tidak divariasi suhu cetak nya dikarenakan suhu leleh minimal yang direkomendasikan untuk material PLA4032D adalah $185^{\circ} \mathrm{C}$. Meningkatkan suhu cetak pada material PLA dapat mengakibatkan perubahan karakteristik seperti modulus elastisitas yang dapat bertambah ataupun berkurang dimana enis PLA 4032D akan bertambah modulus elastisitasnya ketika dinaikan suhu nya [4].

\subsection{Perimeter Width}

Pada pengujian perimeter width dilakukan cetak objek dengan bentuk balok dan dimensi memiliki 3 variasi (10 $\mathrm{mm}, 15 \mathrm{~mm}$, dan $20 \mathrm{~mm}$ ). setelah proses cetak dilakukan pengukuran dimensi dan dihitung error yang terjadi pada sumbu X dan Y. Dapat dilihat dari grafik (Gambar 3) bahwa hasil rata-rata dimensi terukur baik pada pengujian perimeter width $0,2 \mathrm{~mm}$ dan $0,5 \mathrm{~mm}$ tidak terdapat pengaruh yang signifikan.

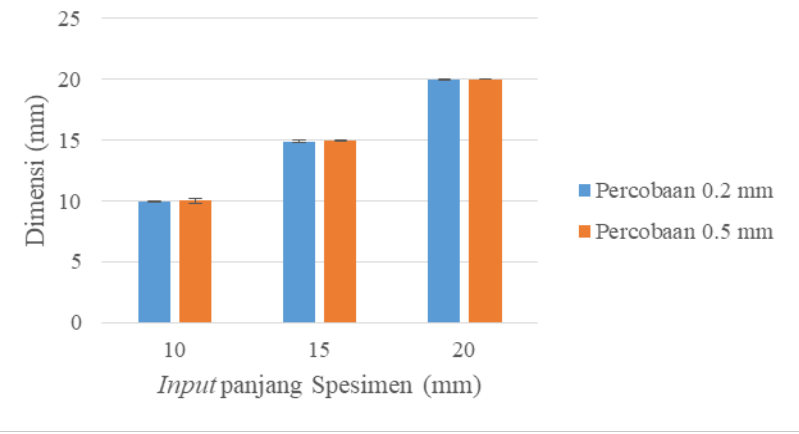

(a)

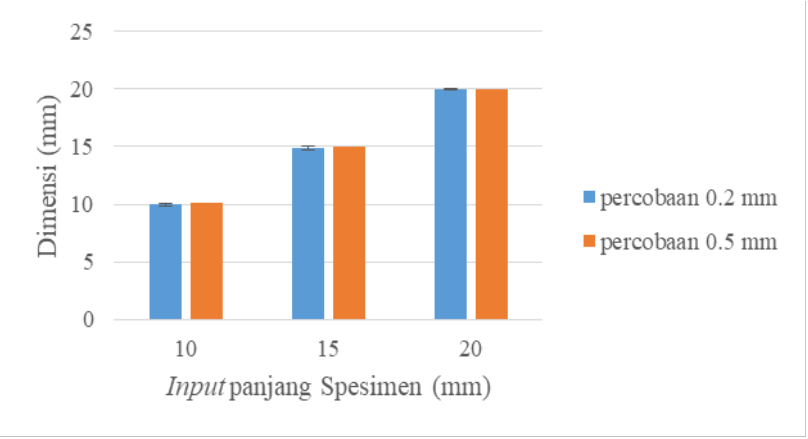

(b)

Gambar 3. Grafik Pengujian Perimeter width (a) Sumbu X, (b) Sumbu Y

\subsection{Akurasi dan kepresisian 3D Printer}

Setelah serangkaian kalibrasi dilakukan, pengujian terakhir adalah mengukur tingkat akurasi dan kepresisian $3 D$ Printer (Gambar 4). Akurasi menunjukan kedekatan nilai pengukuran dari nilai yang seharusnya dan Kepresisian menunjukan seberapa besar penyimpangan nilai pengukuran saat dilakukan perulangan pengukuran pada objek berbeda dengan dimensi sama.

Pengujian dilakukan dengan cara melakukan pengulangan cetak untuk tiap variasi panjang sebanyak 5 kali. Dilakukan pengukuran terhadap objek yang sudah dicetak dan membandingkan dengan input panjangnya. Dari pengujian ini ditunjukkan hasil dari objek cetak sudah sesuai dengan input panjang yang diinginkan. 
Yosef Teddy Budianto dkk /Jurnal Rekayasa Mesin

p-ISSN: 1411-6863, e-ISSN: 2540-7678

Vol.15|No.3|183-190|Desember|2020

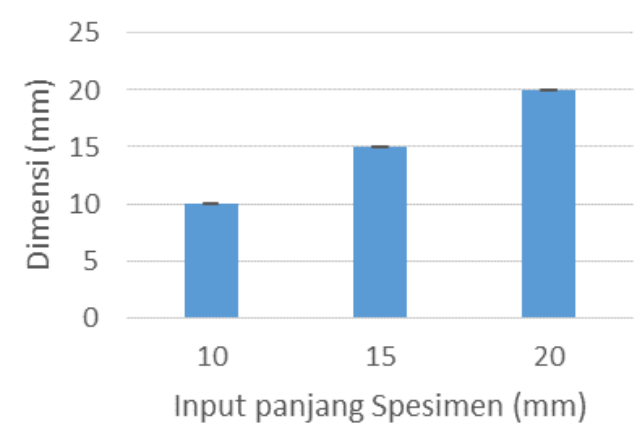

a)

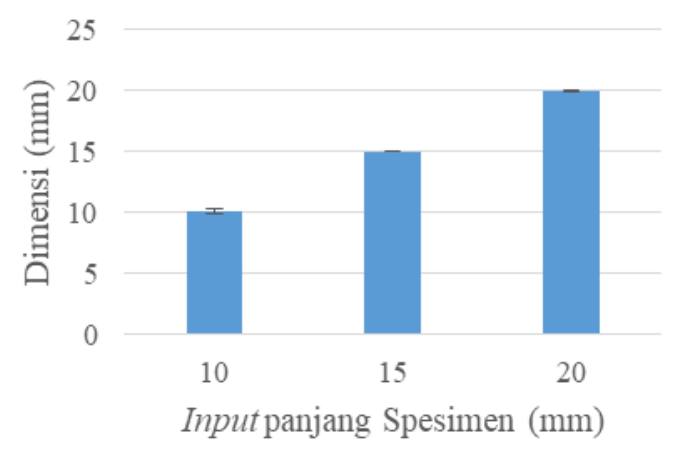

(b)

Gambar 4. Hasil Pengujian Akurasi dan Kepresisian (a) Sumbu X, (b) Sumbu Y

Dapat dilihat melalui grafik diatas bahwa sistem telah berfungsi dengan sangat baik berdasarkan nilai error yang terjadi. Jangkauan error terbesar adalah $\pm 0,06 \mathrm{~mm}$ dan error terkecil adalah $\pm 0,02 \mathrm{~mm}$. Hasil cetak yang sangat baik pada pengujian ini merupakan hasil yang didapat dari kalibrasi yang telah dilakukan terlebih dahulu seperti kalibrasi motor stepper, bed leveling, kalibrasi step ekstruder, layer height, bridging, overhang, oozebane, dan perimeter width.

Setelah dilakukan serangkaian kalibrasi untuk memaksimalkan fungsi dari $3 D$ Printer dan hasil cetak sudah menunjukan hasil yang sangat baik. 3D Printer sudah memenuhi capaian fungsi berrdasarkan perhitungan dari hasil pengujian diperoleh pembulatan akurasi dan kepresisian $3 D$ Printer sebesar 0,1 $\mathrm{mm}$ dimana nilai ini masih berada pada jangkauan error yang dihasilkan oleh alat 3D peinter komersial seperti Makerbot [5].

\subsection{Jarak Laser}

Pengujian dilakukan dengan memberikan daya maksimal $(\mathrm{s}=255)$ dan memberikan variasi jarak laser pada 2 jenis material, yaitu Kardus dan Triplek. Untuk mengetahui efek dari jarak laser terhadap hasil proses laser engraver. Kecepatan gerak laser ditetapkan pada $300 \mathrm{~mm} / \mathrm{min}$.

Tabel 2. Hasil Pengujian Jarak Laser pada Kardus

\begin{tabular}{|c|c|c|c|c|c|}
\hline No. & Material & Jarak Head Laser (mm) & Kecepatan Gerak (mm/min) & Input & Hasil \\
\hline 1 & Kardus & 45 & 300 & Teks & \\
\hline 2 & Kardus & 55 & 300 & Teks & \\
\hline 3 & Kardus & 65 & 300 & Teks & \\
\hline
\end{tabular}


Yosef Teddy Budianto dkk /Jurnal Rekayasa Mesin

p-ISSN: 1411-6863, e-ISSN: 2540-7678

Vol.15|No.3|183-190|Desember|2020

\begin{tabular}{cccccc}
\hline No. & Material & Jarak Head Laser $(\mathrm{mm})$ & Kecepatan Gerak $(\mathrm{mm} / \mathrm{min})$ & Input & Hasil \\
\hline 4 & Kardus & 75 & 300 & Teks & \\
5 & Kardus & 85 & 300 & Teks & \\
\hline
\end{tabular}

Pada material kardus (Tabel 2), garis dengan ketebalan yang dihasilkan terlihat secara visual berbeda-beda pada tiap variasi jarak. Jarak terbaik pertama didapat pada jarak $75 \mathrm{~mm}$ dengan garis yang dihasilkan tegas dan besarnya seragam. Jarak terbaik kedua didapat pada jarak $65 \mathrm{~mm}$ dengan garis yang dihasilkan besarnya seragam namun garis terlihat lebih tipis dibandingkan pada jarak $75 \mathrm{~mm}$.

Tabel 3. Hasil Pengujian Jarak Laser pada Triplek

\begin{tabular}{|c|c|c|c|c|c|}
\hline No. & Material & Jarak Head Laser (mm) & Kecepatan Gerak (mm/min) & Input & Hasil \\
\hline 1 & Triplek & 45 & 300 & Teks & \\
\hline 2 & Triplek & 55 & 300 & Teks & \\
\hline 3 & Triplek & 65 & 300 & Teks & \\
\hline 4 & Triplek & 75 & 300 & Teks & \\
\hline 5 & Triplek & 85 & 300 & Teks & \\
\hline
\end{tabular}

Pada material Triplek dengan ketebalan $5 \mathrm{~mm}$ jarak divariasikan dari $45 \mathrm{~mm}$ sampai $85 \mathrm{~mm}$, dapat dilihat dari Tabel 3 garis yang dihasilkan pada pengaturan jarak $45 \mathrm{~mm}$ dan $85 \mathrm{~mm}$ tidak dapat terlihat secara utuh dan buram. Jarak terbaik didapat pada pengaturan jarak head laser $75 \mathrm{~mm}$.

Berdasarkan kedua material yang digunakan dalam pengujian jarak laser pada material memiliki pengaruh terhadap hasil penandaan, dari kejelasan penandaan, kedalamaan penandaan dan fokus dari garis penandaan. Penyebab dari perbedaan hasil garis ini dapat dilihat dari 2 fakor, yang pertama dari sisi laser diode dan yang kedua dari sisi material 
yang diproses. Laser diode yang digunakan memiliki lensa sehingga juga jangkauan fokus tertentu dilihat dari hasil penandaan yang berbeda-beda ketika dilakukan variasi jarak head laser dari $45 \mathrm{~mm}$ sampai $85 \mathrm{~mm}$. Setiap material memiliki komponen kimia penyusun material yang berbeda-beda. Dilihat pada pengujian dengan jarak head laser 85 $\mathrm{mm}$, hasil pada material kardus dan triplek tidak sama meskipun kecepatan gerak pemakanan dan daya laser nya sama. Pada kardus dan triplek komponen kimia penyusunya mengandung karbon sehingga lebih mudah terjadi penandaan karena terjadi oksidasi ketika dilakukan penandaan dengan laser diode yang menggunakan prinsip radiasi dari intensitas cahaya yang dihasilkan [6].

\section{Kesimpulan}

Dari hasil pembahasan dapat disimpulkan bahwa sistem kontrol mesin dengan fungsi $3 D$ Printer dan Laser Engraver berhasil diwujudkan dan penggantian fungsi dari 3D Printer ke Laser Engraver begitu juga sebaliknya dapat dilakukan dengan mengganti head pada mesin. Pengujian bridging telah dilakukan dengan pengaturan optimal pada suhu hotend $185^{\circ} \mathrm{C}$, suhu heated bed $50^{\circ} \mathrm{C}$ dan feedrate cetak $25 \mathrm{~mm} / \mathrm{min}$ sehingga didapat akurasi dan kepresisian pada proses $3 D$ Printer dengan material PLA sebesar 0,1 mm. Pengujian jarak head laser telah dilakukan untuk menentukan pengaturan optimal pada fungsi Laser Engraver dengan jarak terbaik pada $75 \mathrm{~mm}$. Pengujian kecepatan gerak telah dilakukan untuk menentukan kecepatan efektif pada fungsi Laser Engraver dengan hasil penandaan terbaik pada material kardus $400 \mathrm{~mm} / \mathrm{min}$, pada material triplek $300 \mathrm{~mm} / \mathrm{min}$.

\section{Daftar Pustaka}

[1] Rayna, T., Striukova, L., (2016), From rapid prototyping to home fabrication: How 3D printing is changing business model innovation, Technological Forecasting and Social Change. 2016; 102; p. $214-224$.

[2] Munadi, Rancang-bangun prototipe mesin CNC Laser Engraving dua sumbu menggunakan diode laser, Jurnal Teknik Mesin Indonesia. 2018 April; 13 (1): p.32-37.

[3] Hsieh, C. Development of an integrated system of 3D printer and laser carving, 11th International Microsystems, Packaging, Assembly and Circuits Technology Conference (IMPACT), Taipei. 2016: pp. 420-423.

[4] Coppola, B., Cappetti, N., Di Maio, L., Scarfato, P., Incarnato, L. 3D Printing of PLA/clay Nanocomposites: Influence of Printing Temperature on Printed Samples Properties. Materials, Department of Industrial Engineering, University of Salerno, Italy. 2018.

[5] Pei, E. Evaluation of dimensional accuracy and material properties of the MakerBot 3D desktop printer. Rapid Prototyping Journal. 2015.

[6] Lichovník, J., Malotová, Š., Zelinka, J. Effect of Laser Processing Parameters on Cut Quality after Engraving, Technological Engineering. 2019; 16(1): p. 11-15. 